\title{
A recombinant baculovirus TnGV in Trichoplusia ni larvae using the PIG bombardment method and the CRISPR/Cas9 system
}

\section{Oscar J. Ortiz-Arrazola ${ }^{1}$ and Ma. Cristina Del Rincón-Castro ${ }^{*}$}

\author{
${ }^{1}$ Departamento de Alimentos y Posgrado en Biociencias, División de Ciencias de la Vida. \\ Universidad de Guanajuato. Apdo. Postal 311, 36500 Irapuato Gto. México.
}

*Corresponding author: cdelrincon@ugto.mx

\begin{abstract}
Baculoviruses have been used for the expression of heterologous proteins of biotechnological interest. However, most of these proteins are obtained by homologous co-transfection recombination in cell lines, limiting their use. Recently, the CRISPR/Cas9 system has excelled in its high efficiency in editing specific sequences without the need for insect cell lines. In this work, the CRISPR/Cas9 system was used to edit the genome of Trichopusia ni granulovirus (TnGV) and transformation of insects by the PIG bombardment method. A homologous repair vector (pTnGV101) was designed with regions orf5 and orf7, as well as sgRNA flanking TnGV P10 of this virus. The bombardment transformation was carried out at 175 psi with $40 \%$ of infected $T$. ni larvae, of which $38 \%$ expressed the reporter protein EGFP. These results demonstrate that the CRISPR/Cas9 system and PIG bombardment can be used for genetic modification of baculovirus in vivo.
\end{abstract}

Keywords: Baculovirus, Trichoplusia ni, TnGV, bombardment, CRISPR/Cas9 


\section{Introduction}

Baculoviruses are an important group of entomopathogens that are used to control a wide variety of pest insects (Szewczyk et al., 2006). The Baculoviridae family includes 4 genera: Alphabaculovirus (Nucleopolyhedrovirus or NPV), Betabaculovirus (Granulovirus or GV), Gamabaculovirus (NPV) and Deltabaculovirus (NPV). The baculovirus genome is a doublestranded supercoiled DNA of 82-180 kb (Jehle et al., 2006). Baculoviruses have been widely used for the expression of heterologous proteins (Airenne et al., 2013; Kost et al., 2005). Recombinant strains have been developed, inserting genes into the genome of some baculoviruses with the aim of increasing their virulence. Examples of this strategy are gene insertions coding for scorpion neurotoxins (Carbonell et al., 1988; Stewart et al., 1991), mite toxins (Tomalski, \& Miller, 1991), the diuretic hormone of insects (Maeda, 1989), the sterease of the juvenile hormone (Hammock, et al., 1990), the venom of spiders, genes of anemones (Prikhod'ko et al., 1996) and for the cry genes of Bacillus thuringiensis (Martens et al., 1990; Merryweather et al., 1990).

Recombinant baculoviruses have only been developed in Autographa californica multiple nucleopolyhedrovirus (AcMNPV), and in Bombix mori nucleopolyhedrovirus (BmSNPV) (Kost et al., 2005; Martínez-Solís \& Herrero, 2019; Motohashi et al. 2005). Most genetically modified baculoviruses have been obtained by homologous recombination by co-transfection of viral DNA and a transfer vector in cell lines; or the bacmids system for genetic exchange. Both transfer systems are limited by the few insect cell lines available (Hajós et al., 1998; Luckow et al., 1993). On the other hand, the CRISPR/Cas9 system has been successfully used for the deletion and insertion of genes in cell lines and higher organisms (Esvelt \& Church, 2013; Lin et al., 2016). This method is based on the combination of a DNA endonuclease and a single RNA guide molecule (sgRNA) that directs the nuclease to a complementary target in DNA where it induces double-stranded breaks. In most cases, these lesions are repaired by non-homologous end-union (NHEJ) or homology-directed repair (HDR) that uses a homologous DNA template as a guide (Ran et al., 2013). The bombardment particle release system (originally used to transform plant cells) (Klein et al., 
1988) uses tungsten or gold microparticles that are coated with DNA. These microparticles are inserted into the cell core at high speed. Are currently two types of particle bombardment systems in genetic transformation: the so-called Bio Rad PDS 1000 / HE (drying system) and the particle flow gun (PIG) (wet system) (Finer et al., 1992). The PIG system uses a dry layer of DNA-coated particles on a membrane, which is subjected to a sudden helium trigger. The membrane impacts a metal grid releasing the particles at a high velocity which penetrate the tissues of the white organism (Gunadi et al., 2019; Thomas et al., 2001).

The principal objective of this work was to use the CRISPR/Cas9 system to edit the Trichoplusia ni granulovirus (TnGV) genome in combination with the PIG bombardment technique to obtain a recombinant virus. A repair vector was developed which, when evaluated, showed the potential of baculoviruses to produce recombinant proteins when they do not have insect cell lines for genetic modification.

\section{Materials and methods}

Insects. A colony of Trichoplusia ni was established under insectary conditions at $28^{\circ} \mathrm{C} \pm$ $2^{\circ} \mathrm{C}$, with photoperiod of 14 hours day and 10 hours night and 60-70\% RH. The larvae were fed in modified artificial semi-diet (Guy et al., 1985).

Strains and vectors. The baculovirus strain used in this study was the granulovirus (TnGV) isolated from Trichoplusia $n i$ and the transfer vector pAcUW31 (CLONTECH Laboratories Inc. Palo Alto, CA) was used as a template repair plasmid. The plasmid pU6-BBSI (donated by Izuho Hatada, Addgene plasmid \#128433) was used for sgRNA cloning. Plasmid vector pHSP70-Cas9 (donated by L. B. Voshall, Addgene \#45945) (Gratz et al., 2013) containing protein Cas9 under temperature induction promoter HSP70 of D. melanogaster was used as endonuclease. All plasmids were amplified in the E. coli TOP10F strain (Invitrogen Life Technologies, Carlsbad, CA).

Construction of the repair vector. For the construction of the repair vector, it was used as template pAcUW31, to which the homologous regions ORFlef2/orf603 and orf1629 were 
changed to regions orf5 and orf7 of the wild TnGV baculovirus. These regions were amplified with oligonucleotides

D-ORF5 5'CCGcggagCAAGGGTAGCCTGTCTATTGGAC 3' and R-ORF5 5' ATAAGAATGATCATCGGATTGGTGAAATTTTTCG 3' for a fragment of $855 \mathrm{bp}$; and with D-ORF7 5'ATAAGAATCAGATCAGATG CCGctcgagTTCTTCATCTTCAATATTATGTC3 for a fragment of 3' and 803-ORF7 5'. Once the repair recombination plasmid was constructed ( pTnGV101), the egfp reporter gene was inserted under promoter P10.

Design and cloning of RNA guidance. The sgRNA were designed on the CHOP-CHOP platform (Labun et al., 2019) and synthesized by the commercial house T4 OLIGO. The sgRNA design was based on TnGV region P10 protein, selecting the sgRNA with the highest score within the white region (Table 1). For the assembly of sgRNA, $1 \mu$ of each oligonucleotide was used incubating at $95^{\circ} \mathrm{C}$ for 5 minutes and then cloned in the pU6-BBSI vector. The resulting modified vector was named pU6-BBSI-grna. To verify the cloning of the sgRNA in the pU6-BBSI vector, the cloning site was amplified between T7 and T3 (700$850 \mathrm{pb})$ of the pU6-BBSI-grna vector, with the initiators T7 5'TAATACGACTACTATAGGG and T3 5'GCAATTAACCCTACTAAAGG. The amplified fragments were sequenced at Macrogen Inc.

Table 1. sgRNA designed on the CHOP-CHOP platform

\begin{tabular}{|c|c|c|c|c|c|}
\hline Ranking & Sequence cRNA $\left(5^{\prime}-3^{\prime}\right)$ & $\begin{array}{c}\text { Genomic } \\
\text { localization }^{\text {a }}\end{array}$ & Chain & $\begin{array}{c}\text { GC content } \\
(\%)\end{array}$ & Off targets \\
\hline 1 & AGCGGCCAACCTGCCCGACGTGG & 175 & - & 74 & 0 \\
\hline $2^{*}$ & GCTCGACGCGCAAGCCGCAGCGG & 214 & - & 78 & 0 \\
\hline 3 & TGATCTCGTCCACGTCGGGCAGG & 184 & - & 65 & 0 \\
\hline 4 & TGGTTGATCTCGTCCACGTCGGG & 188 & - & 61 & 0 \\
\hline 5 & CGGCTTGCGCGTCGAGCTTTTGG & 208 & - & 65 & 0 \\
\hline 6 & GCAAGCGCAGCGGTGCAAACGG & 223 & - & 70 & 0 \\
\hline 7 & GACGGTTGGGTTCAGGATGCTGG & 291 & - & 61 & 0 \\
\hline
\end{tabular}

${ }^{a}$ Localization: from the sequence adjacent to the motif (PAM) to the initial ATG of the p10 gene; coding DNA sequence. * CAR sequence used in this study.

Viral DNA extraction. TnGV purified virions were resuspended in $400 \mu 1$ proteinase $\mathrm{K}$ buffer (Tris-HCl $0.01 \mathrm{M}$, EDTA $0,005 \mathrm{M}$, SDS $0.5 \%$ ) and incubated at $60^{\circ} \mathrm{C}$ for 15 minutes. Subsequently, $100 \mu \mathrm{l}$ of proteinase $\mathrm{K}(200 \mu \mathrm{g} / \mathrm{ml})$ was added and incubated at $37^{\circ} \mathrm{C}$ for $2 \mathrm{~h}$. 
DNA extraction was done with phenol:chloroform:isoamyl alcohol (25: 24:1) followed by chloroform:isoamylic alcohol (24:1). The mixture was fractionated by centrifuging at 10.000 g per 5 min. The samples were dialyzed all night using Tris/EDTA buffer. Finally, DNA was stored at $-20^{\circ} \mathrm{C}$ until use in pig co-transfection.

Preparation of gold particles for bombardment with the system PIG. Gold particles of $1 \mu \mathrm{m}$ were used (BioRad, Hercules, USA). USA). The particles were prepared at a concentration of $60 \mathrm{mg} / \mathrm{ml}$ as described by Cabrera-Ponce et al., (1997). The shooting pressures used were 160 and 175 psi. For each shoot pressure, three treatments were used with different DNA concentrations of vectors pTnGV101, pU6-BBSI-RNA, pHSP70/Cas9 and of the wild strain TnGV (6 treatments in total) (Table 2) resuspended in TE buffer (Tris$\mathrm{HCl} 10 \mathrm{~mm}, 1 \mathrm{~mm}$ EDTA, pH 7.9). Each treatment was added $50 \mu \mathrm{l}$ of particle suspension, $50 \mu \mathrm{l}$ of $\mathrm{CaCl} 2(2.5 \mathrm{M})$ and $20 \mu \mathrm{l}$ of spermidine $(0.1 \mathrm{M}$; free base). The suspensions were briefly sonicated, centrifuged for $10 \mathrm{~min}$ at 12,000 g, and the sediment was washed with 400 $\mu l$ absolute ethanol. The particles were centrifuged under the above conditions and resuspended in $60 \mu \mathrm{l}$ absolute ethanol. $10 \mu \mathrm{l}$ of this suspension of particles coated with the four different DNA were used in each bombardment event.

Table 2. Different DNA concentrations used in PIG bombardment

\begin{tabular}{|c|c|c|c|c|c|}
\hline $\begin{array}{c}\text { No. } \\
\text { Treatment/ } \\
\text { Shooting } \\
\text { Pressure }\end{array}$ & $\begin{array}{c}\text { No. of } \\
\text { larvae } \\
\text { used }\end{array}$ & $\begin{array}{c}\text { TnGV DNA } \\
\text { concentration }\end{array}$ & $\begin{array}{c}\text { DNA } \\
\text { concentration } \\
\text { pTnGV101 } \\
\text { repair vector }\end{array}$ & $\begin{array}{c}\text { DNA } \\
\text { concentration } \\
\text { pU6-BbsI- } \\
\text { RNA }\end{array}$ & $\begin{array}{c}\text { DNA } \\
\text { concentration } \\
\text { pU6-BbsI- } \\
\text { RNA }\end{array}$ \\
\hline Control & 20 & 0 & 0 & 0 & 0 \\
\hline $1,175 \mathrm{psi}$ & 20 & $1 \mu \mathrm{g}$ & $1 \mu \mathrm{g}$ & $1 \mu \mathrm{g}$ & $1 \mu \mathrm{g}$ \\
\hline $2,175 \mathrm{psi}$ & 20 & $2 \mu \mathrm{g}$ & $3 \mu \mathrm{g}$ & $3 \mu \mathrm{g}$ & $3 \mu \mathrm{g}$ \\
\hline $3,175 \mathrm{psi}$ & 20 & $2 \mu \mathrm{g}$ & $5 \mu \mathrm{g}$ & $5 \mu \mathrm{g}$ & $5 \mu \mathrm{g}$ \\
\hline $4,160 \mathrm{psi}$ & 20 & $1 \mu \mathrm{g}$ & $1 \mu \mathrm{g}$ & $1 \mu \mathrm{g}$ & $1 \mu \mathrm{g}$ \\
\hline $5,160 \mathrm{psi}$ & 20 & $2 \mu \mathrm{g}$ & $3 \mu \mathrm{g}$ & $3 \mu \mathrm{g}$ & $3 \mu \mathrm{g}$ \\
\hline $6,160 \mathrm{psi}$ & 20 & $2 \mu \mathrm{g}$ & $5 \mu \mathrm{g}$ & $5 \mu \mathrm{g}$ & $5 \mu \mathrm{g}$ \\
\hline
\end{tabular}


Bombardment conditions for the PIG system. Third instar larvae of $T$. $n i$ were used. The insects were placed in $35 \mathrm{~mm}$ Petri dishes at $40 \mathrm{~cm}$ from the filtration unit. They were subsequently shot by HE with a shooting pressure of 160 and 175 psi, under vacuum chamber conditions of $15.75 \mathrm{inHg}$, respectively. Individuals who survived the shoot were placed on artificial diet. The expression of Cas9 (vector pHS70/Cas9) was induced after the bombardment with a thermal shock of $37^{\circ} \mathrm{C}$ for one hour (Gratz et al., 2013). After seven days, the bombardment larvae were analyzed as described in the analysis of the recombinant TnGV EGFP by Dot Blot section.

Recombinant baculovirus TnGV by PCR analysis. The extraction of recombinant TnGV DNA was performed as described above. To detect the egfp reporter gene, oligonucleotides from homologous regions D-ORF5 5'CCGctgagCAAGGTAGCCTCGTCTATTGGAC 3' and R-ORF7 5'CCGctcgagTTCTTCATCTTCAATATTATGTC3' were used using the PCR Reagent System Kit (Invitrogen, Life Technologies Inc.). The reaction mixture was prepared with $100 \mathrm{ng}$ of recombinant TnGV DNA, $200 \mathrm{M}$ dNTP's, MgCl2 3 mm, $100 \mathrm{ng}$ of each primer, 2.5 U Taq DNA polymerase (Invitrogen) and reaction buffer up to a total volume of $50 \mu 1$. The amplification conditions were: $95{ }^{\circ} \mathrm{C}$ for $1 \mathrm{~min}$, followed by 30 cycles of $95{ }^{\circ} \mathrm{C}$ for $30 \mathrm{~s}, 42{ }^{\circ} \mathrm{C}$ for $1 \mathrm{~min}$ and $72{ }^{\circ} \mathrm{C}$ for $2 \mathrm{~min}$, ending amplification at $72{ }^{\circ} \mathrm{C}$ for $7 \mathrm{~min}$. The amplified fragment of 743 bp was visualized by electrophoresis in $1 \%$ agarose gel.

Analysis of the Recombinant TnGV EGFP by Dot Blot. Seven days after infection of $T$. $n i$ larvae by bombardment, treated individuals were collected and analyzed. Each larva was suspended in $10 \mu \mathrm{L}$ PBS, frozen in N2 liquid and homogenized. The suspension was kept in ice. The homogenates were then transferred to a Nylon Biodyne TM membrane (Gaithersburg, EE. USA). Overexpressed EGFP bacterial extract was used as positive control and uninfected $T$. ni larvae as negative control. The membrane with the homogenates and controls was subjected to vacuum for 1 hours to ensure protein binding to the membrane. The membrane was blocked with 5\% skimmed milk prepared in Tris-EDTA buffer (Tris-HCl 10 mm and EDTA $5 \mathrm{~mm}, \mathrm{pH}$ 7) in slow agitation for 1 hours. It was then incubated with a polyclonal anti-GFP antibody (1: 2500) overnight at $4{ }^{\circ} \mathrm{C}$. The membrane was washed five times in PBS buffer supplemented with $0.1 \%$ Tween 20. The membrane was re-incubated overnight with the secondary antibody, Anti-IgG (rabbit conjugated to HRP (horseradish 
peroxidase) (Enzo Life Sciences, Inc., Farmingdale, USA). USA) (1:2500). It was washed five times in PBS buffer. HRP activity was detected with the ImmobilionTM Western Kit (Millipore, Damstadt, Germany).

\section{Results}

Construction of the repair vector. The regions ORFlef2/orf603 and orf1629 of the vector pAcUW31 were replaced by regions orf5 and orf7 from the TnGV baculovirus. orf5 and orf7 were previously amplified from the DNA of the $\mathrm{TnGV}$ wild strain. The resulting repair vector was called pTnGV101. The proper insertion of orf5 and orf7 was corroborated by DNA extraction, obtaining a corresponding band of 8000 bp (Figure 1), and by sequencing of recombinant plasmid.

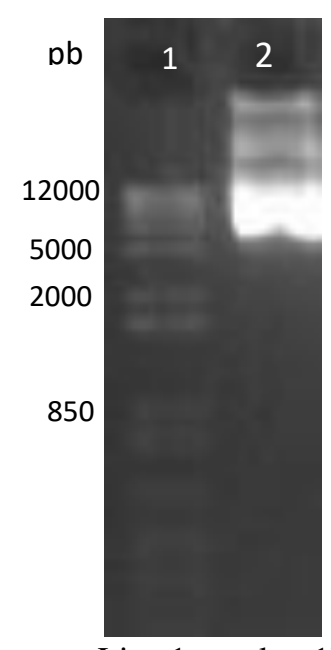

Figure 1. DNA of the pTnGV101 repair vector. Line 1: marker 1Kb Plus DNA Ladder (Invitrogen); line 2: 8000 bp band.

Design and cloning of RNA guides in pU6-BBSI. The sgRNA (23pb) were designed and synthesized from the TnGV gene $p 10$. Both sgRNA were successfully cloned at the BbsI site of plasmid pU6-BbsI, which expresses protein Cas9. The proper insertion of sgRNA at the pU6-BbsI cloning site was corroborated by PCR, obtaining a 700-850 bp amplicon (Figure 2), and by sequencing the modified plasmid pU6-BbsI-RNA. 


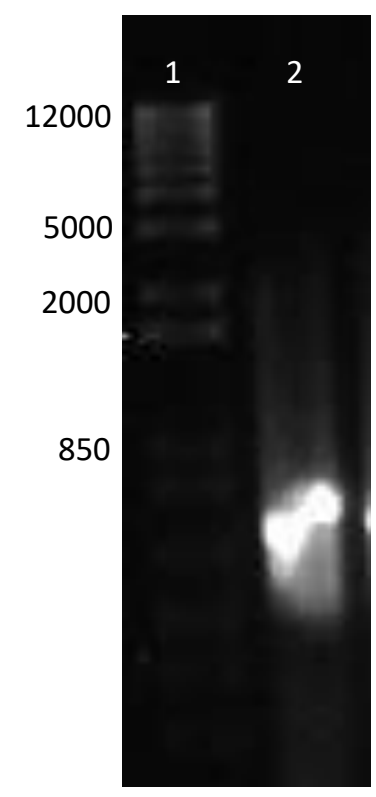

Figure 2. Amplification of the pU6-BbSI-RNA cloning site with gRNAs. Line 1: marker 1Kb Plus DNA Ladder (Invitrogen); Line 2: 850 bp.

PIG co-transfection in $\boldsymbol{T}$. $\boldsymbol{n i}$ larvae. Infection of $T$. $n i$ larvae was achieved by bombardment with the PIG system using gold particles $(60 \mathrm{mg} / \mathrm{ml})$. With treatment 3 (see Tables 2 and 3 ), 175 psi of shooting pressure, $2 \mu \mathrm{g}$ of TnGV DNA and $5 \mu \mathrm{g}$ of DNA of pTnGV101, pU6BBSI-RNA and pHS70/Cas9, respectively, $40 \%$ of the T. ni larvae bombardment were infected. Treatment 3 was followed by treatments 1, 2 (175 psi shooting pressure), 4, 6 and 5 (160 psi shooting pressure); with infection rates of 35,30,10, 10 and 5\%, respectively (Table 3). Seven days after the bombardment of T. ni larvae, surviving individuals showed the characteristic infection caused by TnGV white body, slow movements (Figure 3A), while the control larvae were kept with green body and fully active (Figure 3B).

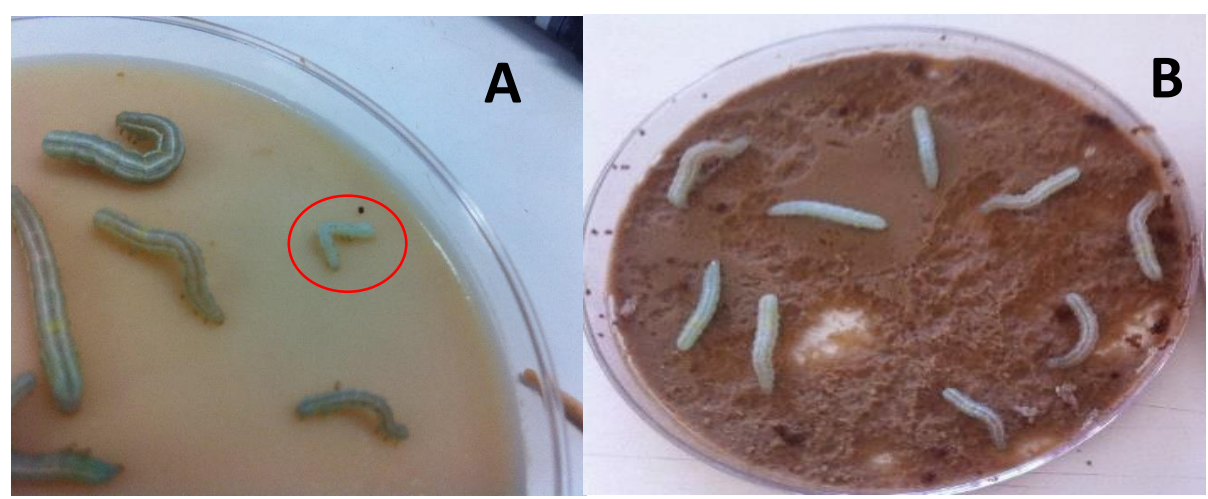

Figure 3. Co-transfection of $T$. $n i$ larvae with recombinant TnGV. A. Larva of $T$. $n i$ infected with recombinant TnGV (red circle). B. T. ni larvae or un-infected (negative control). 
Table 3. T. $n i$ larvae bombardment results using the PIG system.

\begin{tabular}{|c|c|c|c|c|}
\hline $\begin{array}{c}\text { No. Treatment/ Shooting } \\
\text { Pressure }\end{array}$ & $\begin{array}{c}\text { No. of larvae } \\
\text { used }\end{array}$ & $\begin{array}{c}\text { Dead } \\
\text { larvae }\end{array}$ & $\begin{array}{c}\text { Infected } \\
\text { larvae }\end{array}$ & $\begin{array}{c}\text { Infection } \\
\text { rate }\end{array}$ \\
\hline Control & 20 & 0 & 0 & $0 \%$ \\
\hline $1,175 \mathrm{psi}$ & 20 & 2 & 7 & $30 \%$ \\
\hline $2,175 \mathrm{psi}$ & 20 & 3 & 6 & $30 \%$ \\
\hline $3,175 \mathrm{psi}$ & 20 & 2 & 8 & $40 \%$ \\
\hline $4,160 \mathrm{psi}$ & 20 & 1 & 2 & $10 \%$ \\
\hline $5,160 \mathrm{psi}$ & 20 & 2 & 1 & $5 \%$ \\
\hline $6,160 \mathrm{psi}$ & 20 & 2 & 2 & $10 \%$ \\
\hline
\end{tabular}

Detection of EGFP in co- transfected larvae. PIG-infected T. $n i$ larvae were processed for the detection of EGFP by Dot Blot estimating protein expression in $38 \%$ of individuals infected with the first three treatments (175 psi); and 10\% of infected individuals in treatments 4, 5 and $6(160 \mathrm{psi})$.

Detection of the egfp gene by PCR. DNA was extracted from each infected larva with EGFP positive expression. A sample was subsequently selected for each pressure condition (2 samples) and amplification was performed for region orf5 and orf7, with previously reported oligonucleotides. Two amplicons were obtained from 700 to $800 \mathrm{bp}$ (Figure 5). The amplicons obtained were sequenced to corroborate the genetic modification in TnGV. 


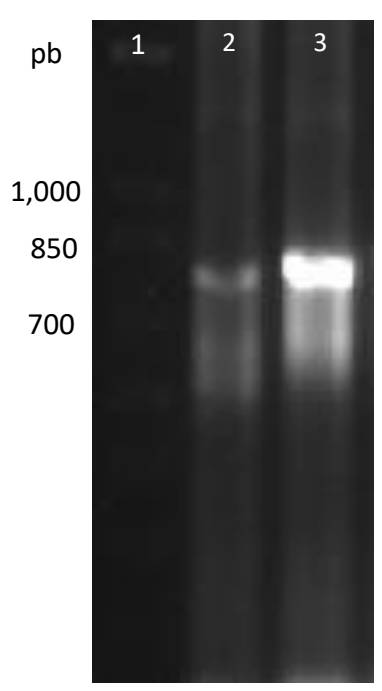

Figure 5. Amplification of egfp integrated into the genome of TnGV. Line 1: marker 1Kb Plus Ladder (Invitrogen); line 2: egfp, 160 psi; line 3: egfp,175 psi.

\section{Discussion}

Baculovirus expression systems have had a profound impact on the production of recombinant proteins in insect cell lines (Hajós et al., 1998; Kost \& Condreay, 1999; Luckow et al. 1993). However, cell lines that are permissible for baculovirus infections are not always available, limiting the collection of recombinant strains. This research demonstrated the potential to use the CRISPR/Cas9 system for genome editing of baculoviruses using the PIG bombardment method. This is very relevant as it allows the expression of heterologous genes in insect larvae.

The CRISPR/Cas9 system has recently been used for genetic modification in some large genome viruses (Ebina et al., 2013; King \& Munger, 2019). A key part of the CRISPR/Cas9 system is the design of sgRNA (Suenaga et al., 2014). For this reason, there are different platforms for the in silico design of sgRNA. For this purpose, the CHOP-CHOP platform was used in this work. Testing sgRNA in vivo maintained the efficiency predicted by the program. In addition to sgRNA, there are other strategies such as dual sgRNA or multiplex 
that have been shown in previous studies to increase efficiency in genome editing (Chen et al., 2014).

The bombardment technique was also used to modify the TnGV genome. It was designed for plant transformation but has also been used to modify different types of organisms including insects (Sanford et al., 1995, Obregón-Barboza et al., 2007). In this work, the PIG method was used, with which a transformation efficiency of $40 \%$ and $38 \%$ was obtained, for two different pressure conditions in the modification of the genome of the baculovirus TnGV. Data similar have previously been reported by Obregón-Barboza et al., (2007). Their experiments consisted in testing different firing pressure conditions and type of microprojectiles (gold and tungsten) but, unlike our work, they used the PDS-1000/HE system, having favorable data for use in baculovirus.

In addition to the above, EGFP expression was very useful for detecting $T$. $n i$ co-transfected larvae. Using the PCR and Dot Blot technique, the infected organisms were individually analyzed and the insertion of this reporter gene into the TnGV virus genome was verified. In other investigations $g f p$ has been used as a reporter gene for the easy detection of genetic transformation of different types of organisms including insects as another of its advantages, is that it can be cloned into transfer vectors (Horn et al., 2002).

The use of two systems, the CRISPR/Cas9 and the bombardment PIG microprojectiles opens a wide variety of alternatives to recombinant viruses, not only to improve their virulence as biological pest control agents, but also as vectors of heterologous protein expression. Of course, this will require the development of standard protocols that should include the design of specific homologous repair vectors, the optimization of bombing conditions, and the greasy design. Theoretically, this technique has the potential to generate recombinant viruses using any baculovirus genus. 


\section{References}

Airenne, K. J., Hu, Y. C., Kost, T. A., Smith, R. H., Kotin, R. M., Ono, C., Matsuura, Y., Wang, S., \& Ylä-Herttuala, S. (2013). Baculovirus: An insect-derived vector for diverse gene transfer applications. Molecular Therapy, 21(4), 739-749. https://doi.org/10.1038/mt.2012.286

Bruce D. Hammock, Bryony C. Bonning, Robert D. Possee, T. N. H. \& S. M. (1990). Expression and effects of the juvenile hormone esterase in a baculovirus vector. Nature, 344, 458-461. https://doi.org/https://doi.org/10.1038/344458a0

Cabrera-ponce, J. L., Lopez, L., Assad-gareia, N., Medina-arevalo, C., Bailey, A. M., \& Herrera-estrella, L. (1997). PlantCell Reports of asparagus ( Asparagus officinalis L .). Plant cell reports, 16(5), 255-260. https://doi.org/https://doi.org/10.1007/BF01088276

Carbonell, L. F., Hodge, M. R., Tomalski, M. D., \& Miller, L. K. (1988). Synthesis of a gene coding for an insect-specific scorpion neurotoxin and attempts to express it using baculovirus vectors. 73, 409-418.

Chen, X., Xu, F., Zhu, C., Ji, J., Zhou, X., Feng, X., \& Guang, S. (2014). Dual sgRNAdirected gene knockout. Scientific Reports, 4(7581), 1-7. https://doi.org/10.1038/srep07581

Ebina, H., Misawa, N., Kanemura, Y., \& Koyanagi, Y. (2013). Harnessing the CRISPR / Cas9 system to disrupt latent HIV-1 provirus. Scientific Reports, 9(3), 1-7. https://doi.org/10.1038/srep02510

Esvelt, K. M., \& Church, G. M. (2013). Cas9 as a versatile tool for engineering biology. Nature methods, 10(10), 957-963. https://doi.org/10.1038/nmeth.2649

Finer, J. J., Vain, P., Jones, M. W., \& McMullen, M. D. (1992). Development of the Particle Inflow Gun. Plant cell reports, 11(7), 323-328. https://doi.org/https://doi.org/10.1007/BF00233358

Gratz, S. J., Cummings, A. M., Nguyen, J. N., Hamm, D. C., Donohue, L. K., Harrison, M. M., Wildonger, J., \& Connor-giles, K. M. O. (2013). Genome Engineering of 
Drosophila with the CRISPR. Genetics, 194(August), 1029-1035. https://doi.org/10.1534/genetics.113.152710

Gunadi, A., Dean, E. A., \& Finer, J. J. (2019). Transient transformation using particle bombardment for gene expression analysis. En S. K. et Al. (Ed.), Transgenic Plants (Vol. 1864, pp. 67-79). Humana Pres. https://doi.org/DOI: 10.1007/978-1-4939-8778$8 \_5$

Guy, R.H., Lepla, N.C., Lye, J.R., Green, C.W., Barrette, S.L., Hollien, K. H. (1985). Trichoplusia ni. En R. F. Singh, P., Moore (Ed.), Handbook of insect rearing (pp. 487494). Elsevier.

Hajós, J. P., Zuidema, D., Kulcsár, P., Heldens, J. G. M., \& Závodszky, P. (1998). Recombination of baculovirus DNA following lipofection of insect larvae Brief Report. Archives of virology, 143(10), 2045-2050. https://doi.org/https://doi.org/10.1007/s007050050441

Horn, C., Schmid, B. G. M., Pogoda, F. S., \& Wimmer, E. A. (2002). Fluorescent transformation markers for insect transgenesis. Insect biochemistry and molecular biology, 32(10), 1221-1235. https://doi.org/https://doi.org/10.1016/s09651748(02)00085-1

Jehle, J. A., Blissard, G. W., Bonning, B. C., Cory, J. S., Herniou, E. A., Rohrmann, G. F., Theilmann, D. A., Thiem, S. M., \& Vlak, J. M. (2006). On the classification and nomenclature of baculoviruses: A proposal for revision. Archives of Virology, 151(7), 1257-1266. https://doi.org/10.1007/s00705-006-0763-6

King, M. W., \& Munger, J. (2019). Editing the human cytomegalovirus genome with the CRISPR I Cas9 system. Virology, 529, 186-194. https://doi.org/10.1016/j.virol.2019.01.021

Klein, T. M., Fromm, M., Weissinger, A., Tomes, D., Sletten, M., Sanford, J. C., Klein, T. M., Frommt, M., Weissingert, A., Tomest, D., Schaaf, S., Slettent, M., \& Sanford, J. C. (1988). Transfer of foreign genes into intact maize cells with. Proceedings of the National Academy of Sciences, 85(12), 4305-4309. https://doi.org/https://doi.org/10.1073/pnas.85.12.4305 
Kost, T. A., \& Condreay, J. P. (1999). Recombinant baculoviruses as expression vectors for insect and mammalian cells. Current opinion in biotechnology, 10(5), 428-433. https://doi.org/https://doi.org/10.1016/s0958-1669(99)00005-1

Kost, T. A., Condreay, J. P., \& Jarvis, D. L. (2005). Baculovirus as versatile vectors for protein expression in insect and mammalian cells. Nature Biotechnology, 23(5), 567575. https://doi.org/10.1038/nbt1095

Labun, K., Montague, T. G., Krause, M., Torres Cleuren, Y. N., Tjeldnes, H., \& Valen, E. (2019). CHOP-CHOP. CHOPCHOP v3: expanding the CRISPR web toolbox beyond genome editing. https://chopchop.cbu.uib.no/

Lin, C., Li, H., Hao, M., Xiong, D., Luo, Y., Huang, C., ... \& Xia, N. (2016). Increasing the Efficiency of CRISPR / Cas9-mediated Precise Genome Editing of HSV-1 Virus in Human Cells. Nature Publishing Group, 6(1), 1-13. https://doi.org/10.1038/srep34531

Luckow, V. A., Lee, S. C., Barry, G. F., \& Olins, P. (1993). Efficient Generation of Infectious Recombinant Baculoviruses by Site-Specific Transposon-Mediated Insertion of Foreign Genes into a Baculovirus Genome Propagated in Escherichia coli. Journal of virology, 67(8), 4566-4579. https://doi.org/https://doi.org/10.1128/JVI.67.8.4566-4579.1993

Martens, J. W., Honée, G., Zuidema, D., van Lent, J. W., Visser, B., \& Vlak, J. M. (1990). Insecticidal activity of a bacterial crystal protein expressed by a recombinant baculovirus in insect cells. Applied and Environmental Microbiology, 56(9), 27642770. https://doi.org/https://doi.org/10.1128/aem.56.9.2764-2770.1990

Martínez-solís, M., \& Herrero, S. (2019). Engineering of the baculovirus expression system for optimized protein production. Applied microbiology and biotechnology, 103(1), 113-123. https://doi.org/https://doi.org/10.1007/s00253-018-9474-7

Merryweather, A. T., Weyer, U., Harris, M. P. G., Hirst, M., Booth, T., \& Possee, R. D. (1990). Construction of genetically engineered baculovirus insecticides containing the Bacillus thuringiensis subsp, kurstaki HD-73 delta endotoxin. Journal of General Virology, 71(7), 1535-1544. https://doi.org/https://doi.org/10.1099/0022-1317-71-71535 
Motohashi, T., Shimojima, T., Fukagawa, T., Maenaka, K., \& Park, E. Y. (2005). Efficient large-scale protein production of larvae and pupae of silkworm by Bombyx mori nuclear polyhedrosis virus bacmid system. Biochemical and biophysical research communications, 326(3), 564-569. https://doi.org/10.1016/j.bbrc.2004.11.060

Obregón-Barboza, V., Del Rincón-Castro, M. C., Cabrera-Ponce, J. L., \& Ibarra, J. E. (2007). Infection, transfection, and co-transfection of baculoviruses by microprojectile bombardment of larvae. Journal of virological methods, 140(1-2), 124-131. https://doi.org/10.1016/j.jviromet.2006.11.017

Prikhod'ko, G. G., Robson, M., Warmke, J. W., Cohen, C. J., Smith, M. M., Wang, P., ... \& Miller, L. K. (1996). Properties of Three Baculovirus-Expressing Genes That Encode Insect-Selective Toxins : $\mu$-Aga-IV, As II , and Sh I. 244(7), 236-244.

Ran, F. A., Hsu, P. D., Wright, J., Agarwala, V., Scott, D. A., \& Zhang, F. (2013). Genome engineering using the CRISPR-Cas9 system. Nature protocols, 8(11), 2281-2308. https://doi.org/https://doi.org/10.1038/nprot.2013.143

S., M. (1989). Increased insecticidal effect by a recombinant baculovirus carrying a synthetic diuretic hormone gene. Biochemical and biophysical research communications, 165(3), 1177-1183. https://doi.org/https://doi.org/10.1016/0006-291x(89)92726-5

Sanford, J. C., Klein, T. M., Wolf, E. D., Allen, N., \& Technol, J. P. S. (1995). Optimizing the Biolistic Process for Different Biological Applications. En Recombinant DNA Methodology II (Vol. 833, Número 1990). ACADEMIC PRESS, INC. https://doi.org/10.1016/B978-0-12-765561-1.50038-2

Stewart, L. M., Hirst, M., López Ferber, M., Merryweather, A. T., Cayley, P. J., \& Possee, R. D. (1991). Construction of an improved baculovirus insecticide containing an insectspecific toxin gene. $\quad$ Nature, 85-88. https://doi.org/https://doi.org/10.1038/352085a0

Suenaga, T., Kohyama, M., Hirayasu, K., \& Arase, H. (2014). Engineering large viral DNA genomes using the CRISPR-Cas9 system. Microbiology and immunology, 58(9), 513522. https://doi.org/10.1111/1348-0421.12180 
Szewczyk, B., Hoyos-Carvajal, L., Paluszek, M., Skrzecz, I., \& Lobo De Souza, M. (2006). Baculoviruses - Re-emerging biopesticides. Biotechnology Advances, 24(2), 143-160. https://doi.org/10.1016/j.biotechadv.2005.09.001

Thomas, J., Bardou, J., Sebastien, L., Mauchamp, B., \& Chavancy, G. (2001). A helium burst biolistic device adapted to penetrate fragile insect tissues . Journal of Insect Science, $1(1), 1-10$.

Tomalski, M. D., \& Miller, L. K. (1991). Insect paralysis by baculovirus-mediated expression of a mite neurotoxin gene. Nature, 352(6330), 82-85. https://doi.org/https://doi.org/10.1038/352082a0 